\title{
Benign hair-follicle derived tumours in the differential diagnosis of basal-cell carcinoma of the eyelids: a clinicopathological comparison
}

\author{
W SIMPSON, A GARNER, AND J R O COLLIN \\ From Moorfields Eye Hospital and the Institute of Ophthalmology, London
}

SUMMARY Benign eyelid tumours derived from hair follicles are rare and frequently misdiagnosed as basal-cell carcinoma when evaluation is based on clinical evidence alone. They include trichoepithelioma, trichofolliculoma, trichilemmoma, and pilomatrixoma. We reviewed 117 such tumours received in the Department of Pathology, Institute of Ophthalmology, London, in the last 30 years, a number which compared with 2447 basal-cell carcinomas seen over the same period. The hair follicle tumours may be safely excised with a narrow margin of clearance, whereas a macroscopic clearance of 3 to $5 \mathrm{~mm}$ or surgery with frozen section histological control is desirable for excision of basal-cell carcinoma. Therefore confirmation by incisional biopsy of the nature of any large lesion suspected of being a basal-cell carcinoma is essential in order to avoid performing an unnecessarily extensive or time consuming excision.

Basal-cell carcinoma (BCC) of the eyelid is the commonest malignant neoplasm in this situation, and its surgical excision was described as long ago as 1755 by Daviel. ${ }^{\prime}$ Effective management requires scrupulous attention to the completeness of removal, and frequently this means excision with generous margins. Conversely, the much rarer benign tumours of hair follicle origin affecting the eyelid may be safely excised with a narrow margin of clearance. But because, perhaps, of their relative rarity or occasional clinical similarity to BCC such tumours can be either overlooked or confused in differential diagnosis and the patients may be subjected to unnecessarily extensive surgery.

The purpose of this paper is to review the pathology of the various types of benign hair follicle tumour, with particular reference to specimens received in the Department of Pathology, Institute of Ophthalmology, London, over the last 30 years and to illustrate the potential for clinical misdiagnosis from cases passing through Moorfields Eye Hospital.

\section{Trichoepithelioma}

Histopathology. The characteristic finding is the Correspondence to Professor A Garner, Institute of Ophthalmology, 17-25 Cayton Street, London EC1V 9AT. presence of multiple horn cysts containing concentrically laminated keratin or a less structured hyaline material (Fig. 1). The cysts lie within the dermis surrounded by a mantle of cells similar to those seen in BCC (Fig. 2), and these cells are frequently arranged in a reticulate manner. Calcification may be seen within the horn cysts, as may a surrounding foreign-body reaction. The usual trichoepithelioma is a nodular lesion, but a desmoplastic variant, which accounts for about $13 \%$ of all such tumours, is also described $^{2}$ in which clumps of epithelial cells are enveloped by prolific dense fibrous tissue (there is no artefactual separation between the epithelial growths and the stroma as is commonly observed in BCC).

The face is a common site for trichoepitheliomas to present. Some $83 \%$ of nodular lesions ${ }^{3}$ and almost all desmoplastic tumours ${ }^{4}$ occur in this situation, but reports in the literature refer to a single example of each variant involving the eyelids alone..$^{45}$ Gray and Helwig $^{3}$ reported just one eyelid tumour in a series of 83 solitary trichoepitheliomas, and Aurora and Blodi $^{6}$ found no eyelid trichoepitheliomas in a series of 678 benign eyelid lesions. Analysis of our own material has revealed 18 cases meeting the histological criteria for such a diagnosis, all of which were of the nodular type. Whether the absence of the desmoplastic variant in the eyelid is significant is 


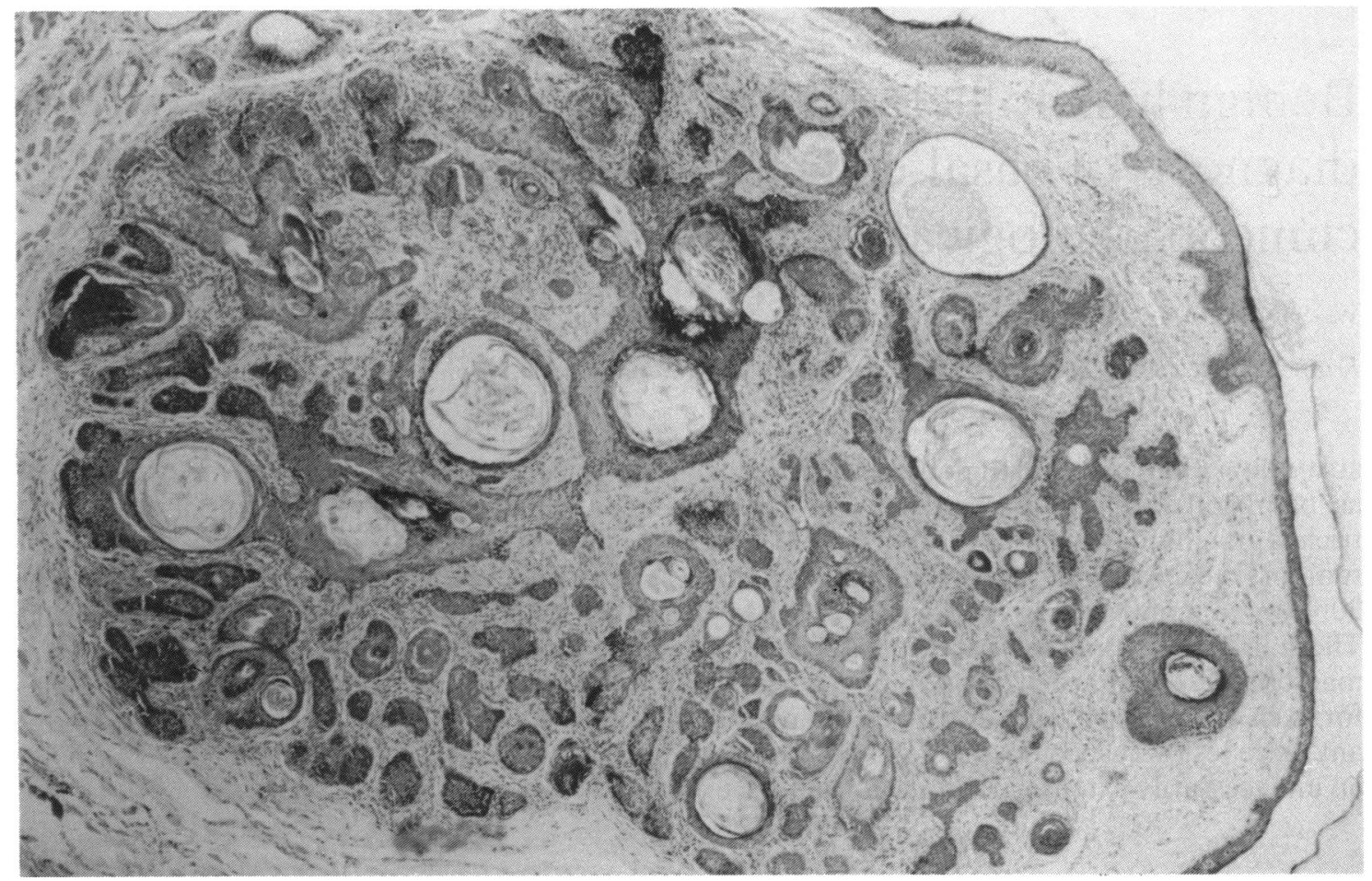

Fig. 1 Trichoepithelioma. A fairly circumscribed nodular tumour consisting of multiple keratinous cysts surrounded by proliferating epithelium is seen within the dermis of the eyelid. (Haematoxylin and eosin, $\times 45$.)

doubtful, especially as the possibility that some such tumours were misdiagnosed as morphoeic BCC cannot be excluded. Although the tumours reviewed by us occurred over a wide age range of 3 to 73 years, presentation before the age of 30 years was unusual and the mean was 46.8 years. In respect of the youngest patient the tumour was thought to have been present from birth. There were 12 male and six female patients in our series.

In cases where the location was known both sides were equally affected, and the upper lid was involved twice as frequently as the lower. It was exceptional for the tumour to arise from the medial canthus, and there was no instance of lateral canthus involvement.

Two of the patients suffered recurrences after 10 and 12 years, but continuing follow-up, covering the next 15 and 14 years respectively, has not been associated with further recurrence.

In the skin, in general, trichoepithelioma may occur as multiple nodules, inherited in an autosomal dominant manner and presenting at about puberty (Brooke's tumour) in association with multiple familial adnexal tumours, ${ }^{7-9}$ blue naevi, ${ }^{10}$ or epidermal naevi." Alternatively the tumour may be sporadic and solitary, presenting as an asympto- matic, flesh-coloured nodule which grows very slowly to attain a maximum diameter of about $5 \mathrm{~mm}$. Such neoplasms may present at any age but are most common in young women. ${ }^{23}$

\section{ILLUSTRATIVE CASE HISTORY}

This is a case of a patient with a trichoepithelioma initially diagnosed as BCC. A 73-year-old Caucasian male normally resident in a sunny subtropical country presented with a three months history of a rapidly growing encrusted lesion of the skin of the lateral part of the lower eyelid and adjacent cheek (Fig. 3). There was no enlargement of regional lymph nodes. The tumour measured $25 \times 20 \mathrm{~mm}$, and was ulcerated and haemorrhagic. A clinical diagnosis of BCC was made, but diagnostic biopsy showed it to be a trichoepithelioma. Subsequently the tumour was excised, with a narrow margin of clearance, and a postauricular whole thickness skin graft was placed to close the defect. The lesion has not recurred in a sixmonth follow-up period.

\section{Trichilemmoma}

Histopathology. The affected cells arise from the 


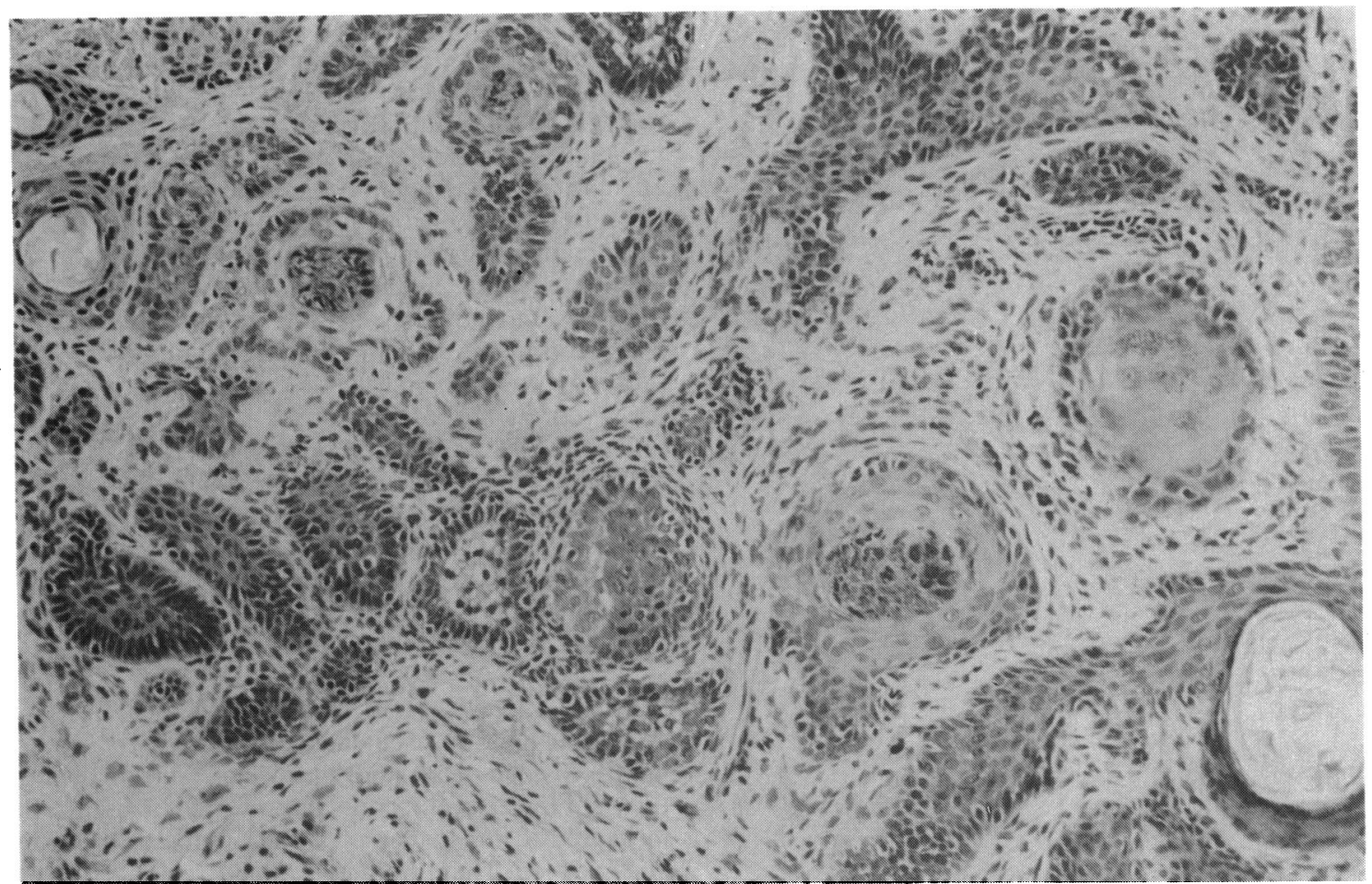

Fig. 2 Trichoepithelioma. Higher magnification of another trichoepithelioma shows the basaloid character of the epithelium in the form of darkly stained cells and marginal palisading. Attempted hair follicle formation is also seen. (Haematoxylin and eosin, $\times 180$.)

outer layer of the hair sheath and as such are rich in glycogen. They proliferate to form acanthotic lobular masses within the dermis and a frequent palisading of the cells at the periphery of each lobule can simulate a BCC (Fig. 4). The basement membrane surrounding the lobules is often thickened (Fig. 5), and one or more hair follicles are usually present. We have seen four examples of this type of tumour involving the eyelid.

Clinically trichilemmoma presents as an asymptomatic, slowly growing, small reddish or yellow nodule and is most common in patients in the sixth decade. Hidayat and Font, ${ }^{12}$ who described a large series of patients with trichilemmoma of the eyelid and eyebrow, commented that some of the tumours were misdiagnosed both clinically and, less often, histologically as BCC. Even more frequent clinical misdiagnoses were verruca and cutaneous horn.

\section{ILLUSTRATIVE CASE HISTORY}

A 46-year-old Caucasian male presented with a small lump measuring up to $3 \mathrm{~mm}$ across at the margin of his left lower lid. The lesion had been present for one year and had bled. A clinical diagnosis of BCC was made but a full thickness excision biopsy showed it to be a trichilemmoma. There has been no recurrence over a nine-month period.

\section{Pilomatrixoma}

Histopathology. The tumours are located in the

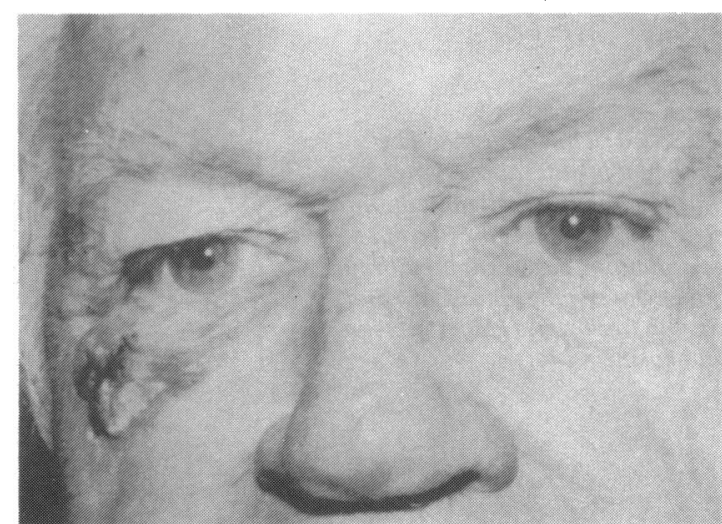

Fig. 3 Trichoepithelioma. This large encrusted lesion affecting the right lower eyelid and adjacent cheek was originally considered to be a basal-cell carcinoma. 


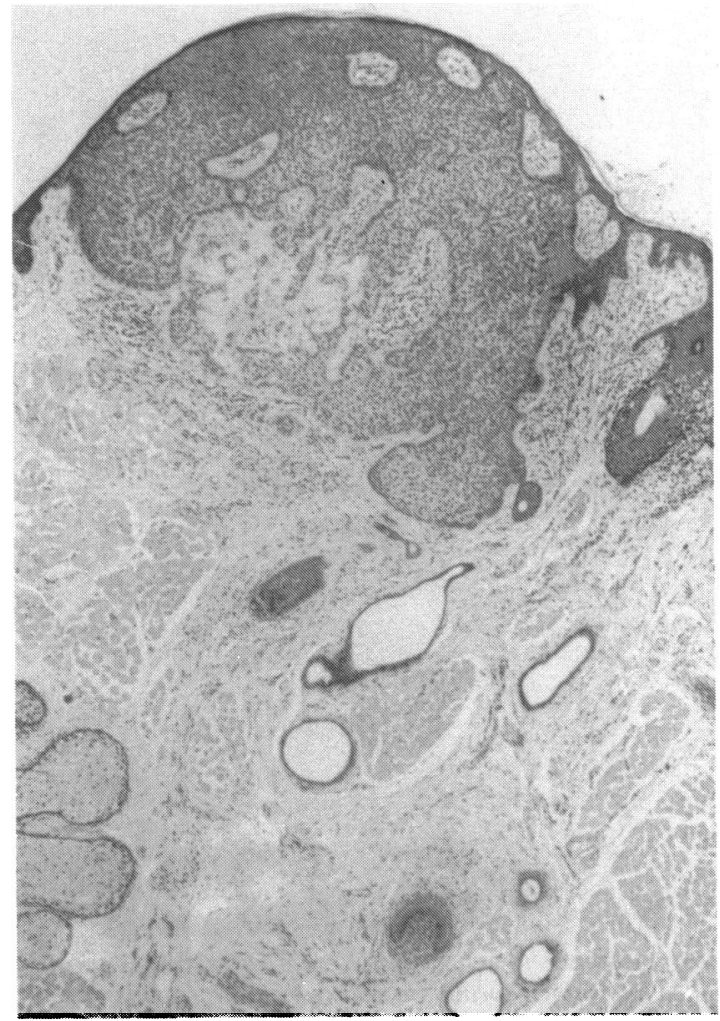

Fig. 4 Trichilemmoma. A solid mass of proliferating epithelium is seen extending into the dermis of the lid with palisading of the cells at the periphery of the downgrowths. (Haematoxylin and eosin, $\times 34$.) dermis and are well demarcated. Large masses of strongly basophilic epithelial cells reminiscent of basal cells merge with areas in which the cells are reduced to ghost outlines with barely distinguishable nuclei. Calcification is common in these latter areas, and a foreign-body giant cell reaction is often seen in the fibrous tissue stroma of the tumour (Figs. 6, 7). An incomplete capsule is often seen.

Pilomatrixoma, which is alternatively referred to as calcifying epithelioma (of Malherbe), can occur at any age although over the skin as a whole some $60 \%$ present within the first two decades. ${ }^{13}$ The upper lid and eyebrow are favoured sites, ${ }^{14}$ is and they constitute about $1 \%$ of all childhood eyelid lesions. ${ }^{16}$ They normally present as very slowly growing, small, hard, solitary nodules beneath normal epidermis. ${ }^{17}$ Largely because of the age difference at the time of presentation, misdiagnosis of pilomatrixoma as BCC is uncommon, though we know of one instance in which $\mathrm{BCC}$ was the preferred clinical diagnosis.

\section{ILLUSTRATIVE CASE HISTORY}

A 29-year-old Caucasian male presented with a ninemonth history of a rapidly growing lump involving the right lower eyelid and adjacent cheek (Fig. 8). It measured $30 \mathrm{~mm}$ in diameter, was tender, encrusted, and had bled. There were no palpable regional lymph nodes. A differential diagnosis of BCC, followed by squamous-cell carcinoma and keratoacanthoma, was entertained before incisional biopsy showed the tumour to be a pilomatrixoma. The lesion was subsequently excised with a narrow margin of clearance, and the defect was repaired with a post-
Fig. 5 Trichilemmoma. The epithelial proliferation shows marginal palisade alignment, more centrally placed clear cells and $a$ conspicuous basement membrane zone between the epithelium and stroma (arrows). (Haematoxylin and eosin, $\times 144$.)

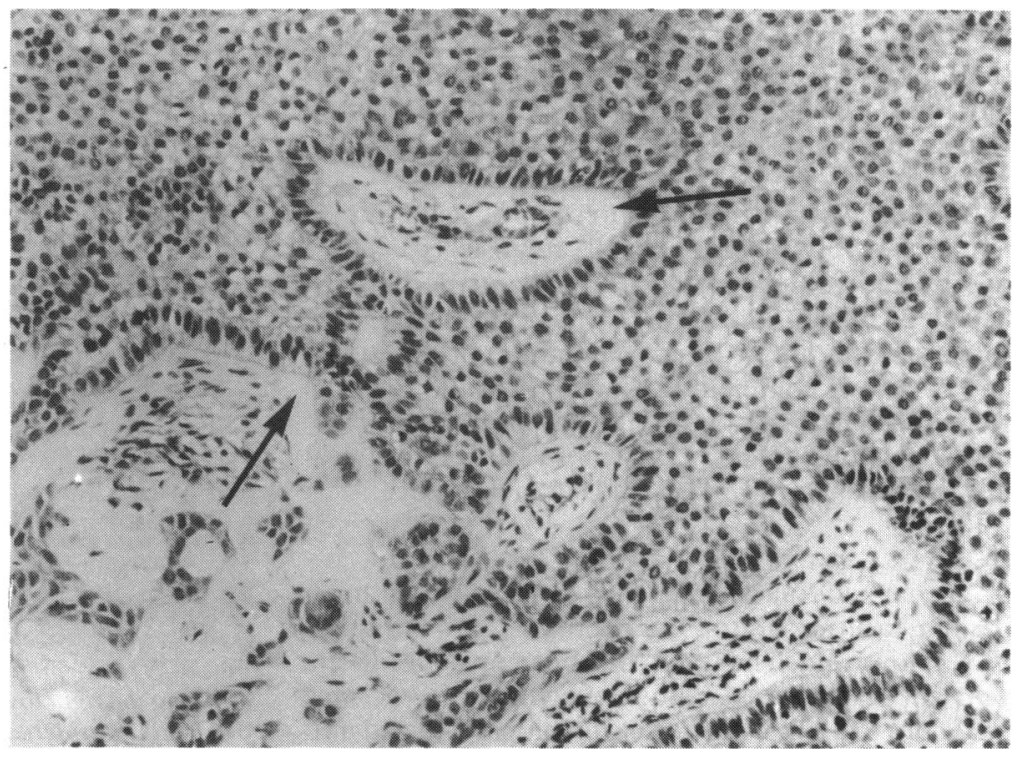




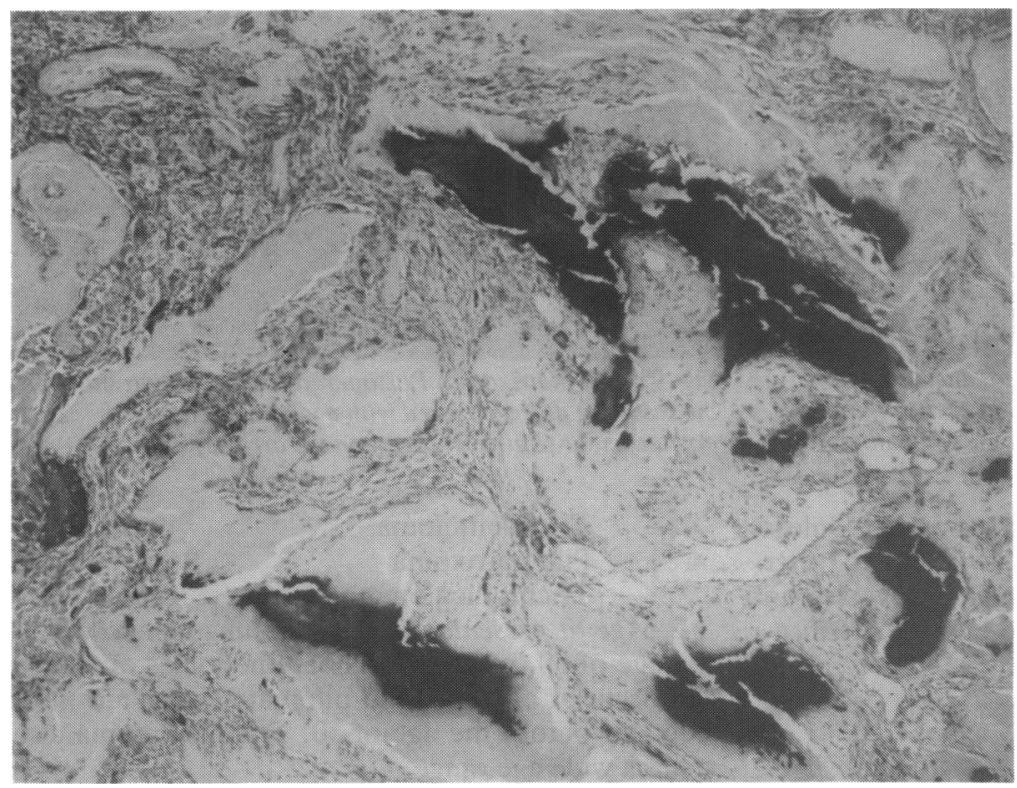

Fig. 6 Pilomatrixoma.

\section{Discernible epithelium is} overwhelmed by areas in which the tumour cells have undergone hyaline change and calcification (dark areas). There is a very cellular intervening stroma. (Haematoxylin and eosin, $\times 36$.)

auricular skin graft (Fig. 9). There has been no recurrence in 18 months.

This case is of particular interest because of the unusually rapid growth rate which was a major cause of clinical confusion. In this respect the tumour is reminiscent of the rare giant pilomatrixomas which have been reported elsewhere, ${ }^{18}$ especially in the parotid region, ${ }^{19-21}$ but not previously in the context of the eyelids.
Although we have not observed such a case, some authors describe a pilomatrix carcinoma on the basis of frequent mitoses in the basaloid cells and invasion of adjacent fat, ${ }^{22}$ muscle, and blood vessels. ${ }^{23-25}$ Consequently it has been proposed that all large pilomatrixomas should be excised with wide margins of clearance as in the surgery of BCC. ${ }^{21}$ On the other hand large size and rapid growth are not in themselves evidence of malignant behaviour and are not

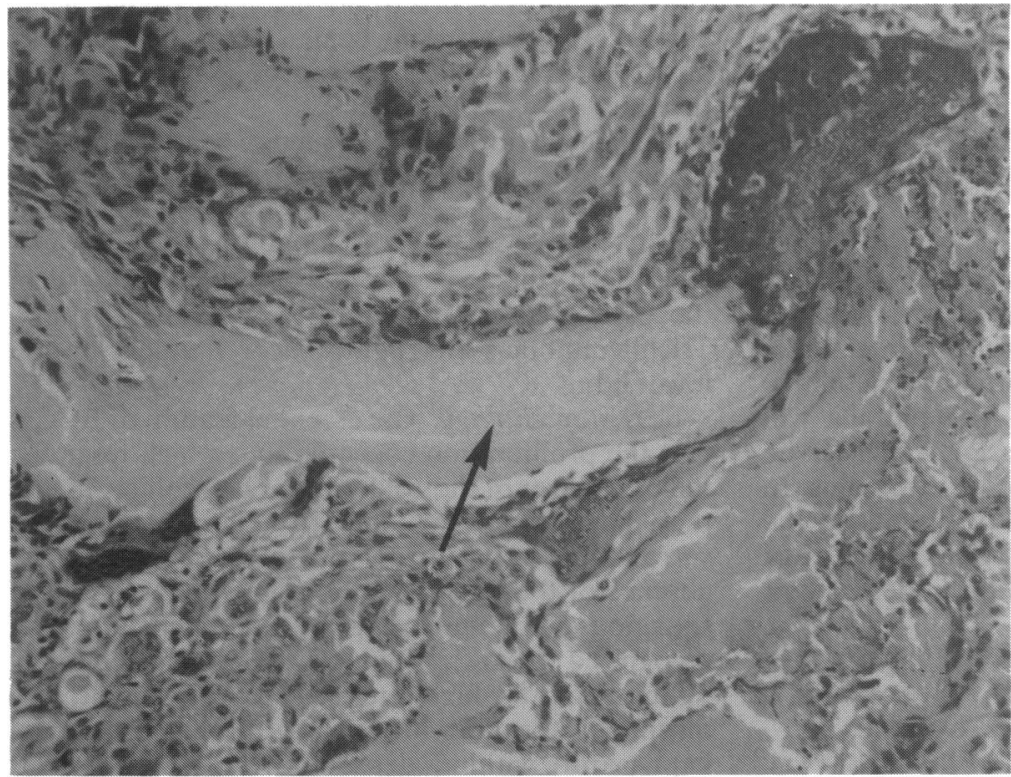

Fig. 7 Pilomatrixoma. At higher magnification viable epithelium is seen together with areas in which it has been reduced to ghost cell outlines (arrow). The surrounding connective tissue stroma includes several multinucleated giant cells. (Haematoxylin and eosin, $\times 144$.) 


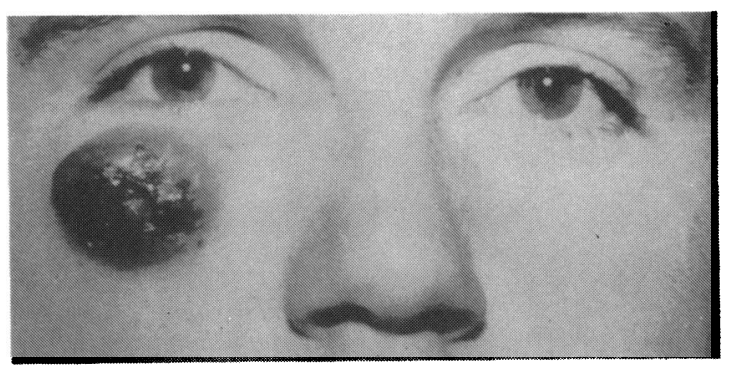

Fig. 8 Pilomatrixoma. There is a raised, encrusted mass involving the right lower eyelid and adjacent cheek, the nature of which was uncertain prior to biopsy examination.

reliable predictors of the risk of recurrence. Unless evidence of abnormal mitotic cell division and other cytological features of malignancy are revealed in biopsy tissue, there would seem to be little justification for wide excision.

\section{Trichofolliculoma}

Histopathology. The essential feature is one or, occasionally, more large cystic spaces containing keratinous material and, frequently, fragments of hair shaft. The cysts are lined by squamous epithelium. Smaller attempts at hair follicle formation are seen radiating from these primary follicles, the fine hairs at the centre of each follicle being surrounded by cells which show peripheral palisading and which are rich in glycogen. The cells forming the inner layer of the hair root often contain eosinophilic trichohyaline granules.

Trichofolliculomas are rare tumours in any part of the skin and are excessively rare on the eyelid. We have observed just one unequivocal case, which involved the upper lid of a 21-year-old male, and know of only three other documented cases concerning the eyelid. ${ }^{2627}$

\section{Further comments}

The object of the present paper is to stress the importance of making a tissue diagnosis in cases of suspected BCC before undertaking definitive surgery, given that occasionally the tumour will prove to be a benign hair follicle lesion which can be safely removed without recourse to wide margins. In which case it is probably useful to summarise the essential clinical and histopathological features of $\mathrm{BCC}$ and compare them with the various benign hair follicle tumours:

1. Incidence. Over a 30 year period (1958-1987) at the Institute of Ophthalmology we have observed:

Basal cell carcinoma

2447 cases

Trichoepithelioma

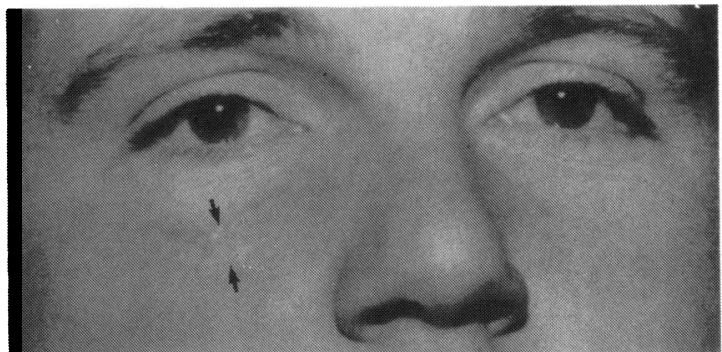

Fig. 9 Pilomatrixoma. Postoperative photograph showing the resulting defect covered with a whole-thickness postauricular skin graft (between the arrows).

$\begin{array}{lr}\text { Trichilemmoma } & 4 \text { cases } \\ \text { Pilomatrixoma } & 94 \text { cases } \\ \text { Trichfolliculoma } & 1 \text { case }\end{array}$

2. Age at presentation. $\mathrm{BCC}$ is uncommon under the age of 50, whereas trichoepitheliomas of the lid can occur at any age, and pilomatrixomas are most frequent before the age of 50 . Trichilemmoma also spans a wide age range.

3. Sex. There is a predominance of males over females in respect of BCC, trichoepithelioma, and, marginally, trichilemmoma. Sex differences do not appear to be significant with regard to pilomatrixoma or trichofolliculoma.

4. Clinical appearance and behaviour. Typically BCC originates as a firm papule which may differ little from the surrounding skin or have a pink translucent appearance. Eventual ulceration leads to the characteristic pearly, rolled edge. Growth is slow and pain is unusual unless there is invasion of bone. However, ulceration is by no means invariable, while conversely, several of the benign hair follicle tumours may occasionally ulcerate and be a source of confusion.

5. Site. The lower lid and medial canthus together account for slightly more than three-quarters of BCCs in the eyelid region..$^{28}$ Upper lid involvement by $\mathrm{BCC}$ is uncommon (less than $7 \%$ in one series), whereas it appears to be the predominant site in the case of trichoepithelioma and pilomatrixoma. Trichilemmomas are slightly more frequent on the lower lid.

6. Histopathology. The essential feature of $\mathrm{BCC}$ is that the proliferation concerns cells which resemble the basal layer of the epidermis or hair follicle in that they have round or oval hyperchromatic nuclei surrounded by a narrow rim of cytoplasm in the absence of the intercellular bridges characteristic of squamous epithelium. A variety of growth patterns is recognised from a solid type that is frequently multicentric, through a reticulate arrangement, to a morphoeic form in which narrow strands of cells run haphazardly within a dense fibrous tissue matrix. It 
is this latter variant which is most aggressive and which can be confused with a desmoplastic trichoepithelioma, so that it is important to look for other evidence of hair follicle differentiation to make the distinction. Mucoid degeneration is common in the connective tissue of BCCs, and there may be separation of the affected stroma from the epithelial cell masses due to processing artefact: such separation is said not to occur in desmoplastic trichoepithelioma.

\section{Conclusion}

Given the potential for diagnostic error two points of practical importance appear to warrant emphasis. The first is that diagnostic biopsy should be undertaken in respect of all but the smallest tumours suspected of being BCCs prior to definitive excision. The second is that, because confusion can also occur at the histopathological level, the correct diagnosis is more likely to result if surgeon and pathologist share their findings.

\section{References}

1 Daviel 1755. Cited by Bennett JP. From noli-me-tangere to rodent ulcer: the recognition of basal-cell carcinoma. Br J Plast Surg 1974; 27: 144.

2 Brownstein MH, Shapiro L. Desmoplastic trichoepithelioma. Cancer 1977; 40: 2979-86.

3 Gray HR, Helwig EB. Epithelioma adenoides cysticum and solitary trichoepithelioma. Arch Dermatol 1963; 87: 102-14.

4 Takei Y, Fukushiro S, Ackerman AB. Criteria for histologic differentiation of desmoplastic trichoepithelioma (sclerosing epithelial hamartoma) from morphea-like basal-cell carcinoma. Am J Dermatopathol 1985; 7: 207-21.

5 Aurora AL. Solitary trichoepithelioma of the eyelid. Indian $J$ Ophthalmol 1974; 22: 32-3.

6 Aurora AL, Blodi FC. Lesions of the eyelids: a clinicopathological study. Surv Ophthalmol 1970; 15: 94-104.

7 Kern F, Hambrick GW Jr. Multiple trichoepithelioma and cylindroma. Birth Defects 1971; 7: 332-3.

8 Magnin PH, Duhm G, Casas JG. Spiradenoma, cutaneous cylindroma and familial multiple trichoepithelioma. Med Cutan Iberio Lat Am 1977; 5: 179-87.

9 Cecchi R, Crudeli F, Fedi E, Gioma A. Multiple trichoepithelioma, cylindroma, eccrine spiradenoma present in the same family. Histologic and histopathogenic considerations. G Ital Dermatol Venereol 1985; 120: 149-52.

10 Newton JA, McGibbon DH. Blue naevus associated with trichoepithelioma: a report of two cases. J Cutan Pathol 1984; 11 : 549-52.

11 Lambert WC, Bilinski DL, Khan MY, Brodkin RH. Trichoepithelioma in a systematized epidermal naevus with acantholytic dyskeratosis. Its occurrence in a black man. Arch Dermatol 1984; 120: 227-30.

12 Hidayat AA, Font RL. Trichilemmoma of eyelid and eyebrow. A clinico-pathologic study of 31 cases. Arch Ophthalmol 1980; 98: 844-7.

13 Moehlenbeck FW. Pilomatrixoma (calcifying epithelioma). A statistical study. Arch Dermatol 1973; 108: 532-4.

14 Ashton N. Benign calcified epithelioma of the eyelid. Trans Ophthalmol Soc UK 1951; 71: 301-7.

15 Boniuk M, Zimmerman LE. Eyelid tumors with reference to lesions confused with squamous carcinoma. II Inverted follicular keratosis. Arch Ophthalmol 1963; 69: 698-707.

16 Doxanas MT, Green WR, Arentsen JJ, et al. Lid lesions of childhood: a histopathologic survey at the Wilmer Institute (1923-1974). J Pediatr Ophthalmol Strabismus 1976; 13: 7-39.

17 Perez RC, Nicholson DH. Malherbe's calcifying epithelioma (Pilomatrixoma) of the eyelid. Clinical features (clinical conference). Arch Ophthalmol 1979; 97: 314-5.

18 Hamilton A, Young GI, Davis RI. Pilomatrixoma mimicking breast carcinoma. Br J Dermatol 1987; 116: 585-6.

19 Sasaki CT, Yue A, Enriques R. Giant calcifying epithelioma. Arch Otolaryngol 1976; 102: 753-5.

20 Rothman D, Kendall AB, Baldi A. Giant pilomatrixoma (Malherbe calcifying epithelioma). Arch Sug 1976; 111: 86-7.

21 Toback JM, Hoover LA, Dudley JP. Pilomatrixoma of the head and neck. Head Neck Surg 1984; 7: 81-4.

22 Lopransri S, Mihm MC Jr. Pilomatrix carcinoma or calcifying epitheliocarcinoma of Malherbe: a case report and review of literature. Cancer 1980; 45: 2368-73.

23 Gromiko N. Zur Kenntnis der bosartigen Umwandlung des verkalkten Hautepitheliomas. Arch Pathol Anat 1927; 265: 103116.

24 Prandetsky AP, Yuzvinkevich AK. Malherbe's epithelioma with signs of malignization. Arch Pathol 1969; 31: 64-6.

25 van der Walt JD, Rohlova B. Carcinomatous transformation in a pilomatrixoma. Am J Dermatopathol 1984; 6: 63-9.

26 Carreras B, Lopez-Martin I, Mellado VG, Guttierrez MT. Trichofolliculoma of the eyelid. Br J Ophthalmol 1981; 65: 214-5.

27 Steffen C, Leaming DV. Trichofolliculoma of the upper eyelid. Cutis 1982; 30: 343-5.

28 Collin JRO. Basal-cell carcinoma in the eyelid region. $\mathrm{Br} J$ Ophthalmol 1976; 60: 806-9.

Accepted for publication $28 \mathrm{July} 1988$. 